\title{
Comparative Abilities of Fasting Plasma Glucose and Haemoglobin A1c in Predicting Metabolic Syndrome among Apparently Healthy Normoglycemic Ghanaian Adults
}

\author{
Nafiu Amidu, ${ }^{1}$ William Kwame Boakye Ansah Owiredu ${ }^{D},{ }^{2}$ Lawrence Quaye ${ }^{D},{ }^{1}$ \\ Peter Paul Mwinsanga Dapare $\mathbb{D}^{1},{ }^{1}$ and Yussif Adams $\mathbb{D}^{1}$ \\ ${ }^{1}$ Department of Biomedical Laboratory Science, University for Development Studies, Tamale, Ghana \\ ${ }^{2}$ Department of Molecular Medicine, Kwame Nkrumah University of Science and Technology, Kumasi, Ghana \\ Correspondence should be addressed to Peter Paul Mwinsanga Dapare; pdapare@uds.edu.gh
}

Received 29 January 2019; Revised 1 June 2019; Accepted 16 July 2019; Published 24 July 2019

Academic Editor: Jose Tellez-Zenteno

Copyright (C) 2019 Nafiu Amidu et al. This is an open access article distributed under the Creative Commons Attribution License, which permits unrestricted use, distribution, and reproduction in any medium, provided the original work is properly cited.

\begin{abstract}
There are arguments as to whether haemoglobin Alc (HbAlc) better predicts Metabolic syndrome (MetS) than fasting plasma glucose. The aim of the study was to explore the comparative abilities of HbAlc and Fasting plasma glucose (FPG) in predicting cardiometabolic risk among apparently healthy adults in the Tamale metropolis. This study was a cross-sectional study conducted in the Tamale metropolis from September, 2017, to January, 2018, among one hundred and sixty (160) apparently healthy normoglycemic adults. A self-designed questionnaire was administered to gather sociodemographic data. Anthropometric and haemodynamic data were also taken and blood samples collected for haemoglobin Alc (HbAlc), fasting plasma glucose (FPG), and lipid profile. MetS was classified using the harmonised criteria as indicated in the joint interim statement (JIS). Out of the 160 participants, $42.5 \%$ were males and $57.5 \%$ were females. FPG associated better with MetS and other cardiovascular risk markers, compared to HbAlc. FPG had the largest area under curve for predicting MetS and its components. This study shows a stronger association between FPG and MetS compared with haemoglobin Alc; it also provides evidence of a superior ability of FPG over $\mathrm{HbAlc}$ in predicting MetS and other adverse cardiovascular outcomes in apparently heathy normoglycemic individuals.
\end{abstract}

\section{Background}

Metabolic syndrome (MetS) is a set of closely associated cardiometabolic risks [1], like obesity, dyslipidemia, hypertension, and hyperglycemia and is seen as a powerful indicator of diabetes and cardiovascular disease (CVD) $[2,3]$. The prevalence of metabolic syndrome continues to be on the rise; this is in part as a result of rapid urbanization with the related variations in nutrition and physical activity [4]. Worldwide the prevalence of metabolic syndrome has been reported as being between $10 \%$ and $84 \%$ [5]. In Africa, prevalence of $2.1 \%$ to $34.7 \%$ has been reported in several studies from around the continent $[6,7]$. In Ghana, a prevalence of metabolic syndrome between $6 \%$ and $21.2 \%$ has been reported [8] using different criteria.
Haemoglobin Alc (HbAlc), a result of nonenzymatic glycosylation of the $\beta$-chain of haemoglobin, is made in proportion to the rise in blood glucose levels. It has been considered a preferable tool since HbAlc assay has superior technical advantages compared to the estimation of plasma glucose; it can be measured in the nonfasted state and has greater reproducibility than fasting glucose $[9,10]$. HbAlc is a set-up marker of long haul glycemic control in individuals with diabetes mellitus (DM), and increased HbAlc levels are linked with an increased risk for later microvascular and macrovascular illness [11].

The fasting plasma glucose (FPG) cut-off figure for MetS may differ among various populaces. There are numerous reports recommending that HbAlc is superior to FPG in forecasting cardiometabolic risk even in nondiabetic individuals 
[12-14], with many others proposing that HbAlc may be an essential marker for MetS, but it stays a controversy [15-17]. However, HbAlc may be influenced by various haematologic, genetic, and disease-related factors [18]. The most important factors globally affecting HbAlc levels are some anaemias, haemoglobinopathies, and disorders linked with increased red blood cell turnover like malaria $[9,19]$.

A $1 \%$ rise in $\mathrm{HbAlc}$ raises the risk of CVD by $18 \%$ and positive relation between CVD and $\mathrm{HbAlc}$ has been shown in nondiabetic individuals even within normal values of $\mathrm{HbAlc}$ [20]. Many population-based studies from Western nations have investigated the link between $\mathrm{HbAlc}$ and the risk of CVDs (MetS) among nondiabetics [14, 21, 22], while only a few studies were from Africa and for that matter Ghana has examined this issue. Moreover, there is scarce evidence about whether or not adding HbAlc to other possible risk factors improves the ability to predict the Metabolic syndrome.

Previous studies have related $\mathrm{HbAlc}$ to glucose and weighed the option of replacing glucose with HbAlc for the criterion or adding HbAlc as an extra criterion for diabetes $[17,23-26]$. However, data on the use of HbAlc as an indicator of MetS particularly in nondiabetic people are scanty and inconclusive, with some studies supporting the possible use of HbAlc as a marker for MetS, while other studies show divergence $[15,24,27,28]$. While some studies have observed the importance of haemoglobin Alc in MetS, few have studied it in individuals with normal glucose levels. The aim of the study was to explore the comparative abilities of HbAlc and FPG in predicting metabolic syndrome in apparently healthy normoglycemic adults within the Tamale metropolis of Ghana.

\section{Methods}

2.1. Subjects. This study was a cross-sectional study conducted among apparently healthy adults (18 years and above) with no history of diabetes within the Tamale metropolis from September, 2017, to January, 2018.

2.1.1. Exclusion Criteria. Diabetics, hypertensives, persons treating diabetes or hypertension, persons with a fasting blood glucose $>7.0 \mathrm{mmol} / \mathrm{l}$ or $\mathrm{HbAlc} \geq 6.5 \%$ at the time of the study, pregnant women, persons showing signs of any acute illnesses, and persons with other chronic diseases were excluded from this study.

2.1.2. Sample Size. The minimum sample size for the study was calculated to be 105 adults, based on the assumption that $7.4 \%$ of the normal adult populations have metabolic syndrome [29], with an expected difference of 5\% between the sample and the general population and a type I error $(\alpha)$ of 0.05 .

This study was limited to only apparently healthy adults who answered at least $75 \%$ of the questions in the questionnaire and did not have an FPG of $>7.0 \mathrm{mmol} / \mathrm{l}$ or an HbAlc of $>6.5$; hence, the sample size was recalculated to adjust for any possible loss of respondents. Assuming a response rate of $90 \%$, the sample size was recalculated to be approximately
117. One hundred and twenty (120) participants were therefore targeted for this study.

\subsection{Data Collection}

2.2.1. Sociodemographic and Anthropometric Data. A selfdesigned semistructured questionnaire was administered to consented study participants for sociodemographic data. Weight to the nearest $0.1 \mathrm{~kg}$ was measured using a digital flat floor weighing scale (with weighing capacity of $250 \mathrm{~kg}$ ) manufactured by SECA (Hamburg, Germany) and height to the nearest $1 \mathrm{~cm}$ was measured using a portable microtoise (measuring range: $0 \mathrm{~cm}$ to $220 \mathrm{~cm}$ ) manufactured by SECA. Waist circumference (to the nearest centimetre) was measured with a Gulick II spring-loaded measuring tape (Gay Mill, WI) midway between the inferior angle of the ribs and the suprailiac crest. Hip circumference was measured as the maximal circumference over the buttocks in centimetre.

2.2.2. Blood Pressure. Blood pressure was measured in sitting position, with a sphygmomanometer cuff and a stethoscope. Measurements were taken from the left brachial artery after subjects had been sitting for at least five (5) minutes in accordance with the recommendation of the American Heart Association [30]. Triplicate measurements were taken with a five (5) minute rest interval between measurements and the mean value was recorded to the nearest $2.0 \mathrm{mmHg}$.

2.2.3. Sample Collection, Preparation, and Analysis. Ten milliliters $(10 \mathrm{ml})$ of venous blood sample was collected under strict aseptic conditions from each participant in the morning between 07.00 and 09.00 GMT into fluoride oxalate tube, Serum Separator Tubes (SST), and ethylenediaminetetraacetic acid (EDTA) anticoagulated tube (Becton Dickinson, Rutherford, NJ), after an overnight (8-12 hours) fast. Samples in the fluoride oxalate tubes were centrifuged and plasma was used for glucose measurement (within 2 hours after sample collection) using the Glucose oxidase peroxidase (GOD-POD) method whilst samples in the SST were centrifuged at $3000 \mathrm{~g}$ for 5 minutes and the serum was aliquoted and stored in cryovials at a temperature of $-80^{\circ} \mathrm{C}$ until time for biochemical assays. Lipid profile and fasting blood glucose levels were determined using the Mindray BS-240 Chemistry Analyser (Mindray, China); MedSource Diagnostics reagents were used in all of these assays. The anticoagulated (EDTA) blood was used for the HbAlc Assay using the MedSource Diagnostics reagents for Glycosylated Haemoglobin (A1-fast fraction) test kit which uses the Cation Exchange Method. For the within run (intra-assay) precision, a \% CV was 2.7 in normal HbAlc samples and 1.7 in elevated HbAlc samples was quoted while for the run to run (Inter run) precision a \% CV was 4.1 for normal samples and 4.6 for elevated samples were quoted by manufacturers. Samples from subjects with haemoglobinopathies or decreased erythrocytes survival times may show incorrect results. This method is not listed in the 2019 National Glycohemoglobin Standardization Program (NSGP) method traceability list. 


\subsection{Definitions of Metabolic Syndrome}

2.3.1. Metabolic Syndrome: Harmonised Criteria by the Joint Interim Statement (JIS). Metabolic syndrome was defined to include individuals with any three or more of the following five components: (1) abdominal obesity (waist circumference, Male $\geq 94$, Female $\geq 80$ ), (2) high triglyceride $\geq 1.7 \mathrm{mmol} / \mathrm{L}$ (150 mg/dl), (3) low HDL-C: Male $<1.0$, Female $<1.3 \mathrm{mmol} / \mathrm{L}$, (4) High BP (systolic BP $\geq 130 \mathrm{~mm} \mathrm{Hg}$ or diastolic BP $\geq 85$ $\mathrm{mm} \mathrm{Hg}$ or treatment of hypertension), and (5) high fasting glucose $\geq 5.6 \mathrm{mmol} / \mathrm{l}[31]$.

2.4. Statistical Analysis. All analyses were performed using MedCalc ${ }^{\circledR}$ version 10.2.0.0 (www.medcalc.be) for windows and GraphPad version 6.0, San Diego, California, USA. Unpaired T-test was used to compare continuous variables. Association between variables was assessed with linear regression analysis. Receiver Operator Characteristics (ROC) was used to compare the relative abilities of various parameters to predict MetS and other cardiovascular risk factors. In all statistical analyses, a $\mathrm{p}$ value of $<0.05$ was considered significant.

\section{Results}

3.1. General Characteristics of Studied Population. A total of 160 complete questionnaires were analysed, of which 68 (42.5\%) were males and 92 (57.5\%) females. Subjects with metabolic syndrome were significantly older than subjects without the metabolic syndrome. The average HbAlc and FPG of the study population were $4.8 \pm 1.2 \%$ and $4.95 \pm 0.92$ $\mathrm{mmol} / \mathrm{L}$, respectively. These parameters were higher in respondents with MetS; however, only the difference in FPG was statistically $(\mathrm{p}<0.001)$ significant as shown in Table 1

\subsection{Biochemical Parameters of Studied Population Stratified} by Gender. Table 2 summarises the biochemical parameters of the studied population stratified by gender. Female respondents were older $(43.8 \pm 14.3$ years $)$ than the male $(41.4 \pm 14.8$ years) but this was not statistically significant. Female respondents with MetS however were significantly older than those without MetS. In females only, FPG was significantly higher in MetS as shown in Table 2.

\subsection{Biochemical Characteristics according to MetS Score.} Table 3 shows the anthropometric and biochemical variations in MetS scores. Generally, FPG significantly showed an increasing trend while moving from a score of 0 to a score of 3 or more.

3.4. Association between HbAlc, FPG, Lipid Parameters, and MetS Score. A linear regression between HbAlc, FPG, and selected cardiometabolic risk is shown in Table 4. HbAlc had significant positive association with triglyceride and VLDL-c. A percentage increase in $\mathrm{HbAlc}$ results in a 0.12 mmol $\left(\mathrm{r}^{2}=0.03, \mathrm{p}<0.05\right)$ increase in Triglyceride and 0.05 mmol $\left(r^{2}=0.03, p<0.05\right)$ increase in VLDL-c. FPG however showed significant positive association with SBP, DBP, total cholesterol, triglyceride, and VLDL-c. A $1 \mathrm{mmol} / \mathrm{L}$ increase in FPG is associated with an increase in $0.33 \mathrm{mmol} / \mathrm{L}\left(\mathrm{r}^{2}=0.05\right.$, $\mathrm{p}<0.01)$ of total cholesterol, $0.21 \mathrm{mmol} / \mathrm{L}\left(\mathrm{r}^{2}=0.05, \mathrm{p}<0.01\right)$ of triglyceride, and a $0.10 \mathrm{mmol} / \mathrm{L}\left(\mathrm{r}^{2}=0.05, \mathrm{p}<0.01\right)$ increase in VLDL-c.

3.5. Receiver Operator Characteristics (ROC) for HbAlc and FPG in the Studied Population. The ROC curves and the Area under Curve (AUC) between HbAlc and FPG against MetS and its individual components are shown in Figure 1 and Table 5. FPG had the largest AUC for all variables assessed, that is, MetS, 2 or more nonglycemic components, abdominal obesity, elevated BP, elevated triglyceride, and reduced HDLc (Table 5).

\section{Discussion}

The role of impaired glucose metabolism in the pathogenesis of MetS and its adverse effects on CVDs and diabetes outcomes has been well documented [32, 33]. Hyperglycemia is known to compound the problem in MetS through the formation of advanced glycation end products [34].

Fasting plasma glucose and haemoglobin Alc measurements have been used over the years in the diagnosis of impaired glucose metabolism. However, proper consensus has not been reached about which there is a better diagnostic tool, associates better with cardiometabolic risk, and can be used as a predictive tool for MetS, especially among normoglycemic individuals. Some studies have shown that haemoglobin Alc associates better with cardiometabolic risk $[16,24,35]$.

This study however found that haemoglobin A1c does not associate better with cardiometabolic risk and has no superior ability in predicting the presence of MetS among a normoglycemic northern Ghanaian population. Succurro and Marini [23] pointed out that the classification of MetS using a HbAlc criterion instead of glucose performed worse in detecting some subjects who still had an unfavourable cardiometabolic risk profile. Several other studies have reported similar findings, especially among a normoglycemic population [36].

The adverse effects of impaired glucose metabolism and diabetes are as a result of the elevated glucose levels and not elevated levels of haemoglobin A1c which is only reflective of a chronic exposure to high plasma glucose concentration [37]. There is evidence that each of the glycemic measures used to identify prediabetes represents a different domain of glucose metabolism. While FPG reflects basal dysglycemia, HbAlc reflects chronic exposure to basal and postprandial hyperglycemia [37]. A nonlinear relationship between glycemia and the haemoglobin Alc in normoglycemic populations has been observed in a number of studies which have shown that glycemia may be a less important determinant of hemoglobin glycation and that other factors operate to produce consistent changes in HbAlc. Potential explanations for this variation in hemoglobin glycation at or near normal glucose levels have focused on interindividual variation in red cell turnover [38], differences between the 
TABLE 1: Biochemical parameters of studied population stratified by MetS.

\begin{tabular}{|c|c|c|c|c|}
\hline Variables & $\begin{array}{c}\text { Total } \\
(n=160)\end{array}$ & $\begin{array}{c}\text { No MetS } \\
(\mathrm{n}=132)\end{array}$ & $\begin{array}{c}\text { MetS } \\
(n=28)\end{array}$ & $\mathrm{P}$ value \\
\hline Age (years) & $42.8 \pm 14.5$ & $41.6 \pm 14.6$ & $48.2 \pm 12.9$ & 0.030 \\
\hline HbAlc (\%) & $4.8 \pm 1.2$ & $4.8 \pm 1.2$ & $5.2 \pm 1.3$ & 0.080 \\
\hline $\mathrm{FPG}(\mathrm{mmol} / \mathrm{L})$ & $5.0 \pm 0.9$ & $4.8 \pm 0.9$ & $5.8 \pm 0.7$ & $<0.001$ \\
\hline
\end{tabular}

HbAlc: Haemoglobin Alc and FPG: Fasting Blood Glucose. Data are presented as mean \pm SD and compared using T-test.

TABLE 2: Biochemical parameters of studied population stratified by gender.

\begin{tabular}{|c|c|c|c|c|c|c|}
\hline \multirow[b]{2}{*}{ Variables } & \multicolumn{3}{|c|}{ Male } & \multicolumn{3}{|c|}{ Female } \\
\hline & $\begin{array}{c}\text { Total } \\
(\mathrm{n}=68)\end{array}$ & $\begin{array}{c}\text { No MetS } \\
(\mathrm{n}=60)\end{array}$ & $\begin{array}{l}\text { MetS } \\
(n=8)\end{array}$ & $\begin{array}{c}\text { Total } \\
(\mathrm{n}=92)\end{array}$ & $\begin{array}{c}\text { No MetS } \\
(\mathrm{n}=72)\end{array}$ & $\begin{array}{c}\text { MetS } \\
(\mathrm{n}=20)\end{array}$ \\
\hline Age (years) & $41.4 \pm 14.8$ & $41.8 \pm 15.2$ & $38.6 \pm 10.9$ & $43.8 \pm 14.3$ & $41.5 \pm 14.2$ 抹 & $52.0 \pm 11.8$ \\
\hline HbAlc (\%) & $4.8 \pm 1.3$ & $4.8 \pm 1.3$ & $5.1 \pm 1.1$ & $4.9 \pm 1.2$ & $4.7 \pm 1.1$ & $5.3 \pm 1.3$ \\
\hline FPG $(\mathrm{mmol} / \mathrm{L})$ & $5.0 \pm 0.9$ & $5.0 \pm 0.9$ & $5.6 \pm 0.7$ & $4.9 \pm 1.0$ & $4.6 \pm 0.9$ 枺 & $5.8 \pm 0.7$ \\
\hline
\end{tabular}

HbAlc: Haemoglobin Alc and FPG: Fasting Blood Glucose. Data are presented as mean \pm SD and compared using T-test. $\neq$ Comparing females with MetS with females without MetS. Comparison is significant at the 0.05 level, $\neq \ddagger$ Comparison is significant at the 0.01 level, and $\ddagger \ddagger$ Comparison is significant at the 0.001 level.

TABLE 3: Biochemical characteristics stratified by MetS component score.

\begin{tabular}{lccccc}
\hline \multirow{2}{*}{ Variable } & \multicolumn{3}{c}{ MetS score } & & \\
& $0(\mathrm{n}=42)$ & $1(\mathrm{n}=52)$ & $2(\mathrm{n}=38)$ & $\geq 3(\mathrm{n}=28)$ & F Value \\
\hline Age (years) & $34.6 \pm 11.8$ & $42.4 \pm 14.2$ & $48.3 \pm 15.0$ & $48.2 \pm 12.9$ & 8.66 \\
HbAlc (\%) & $4.8 \pm 1.1$ & $4.8 \pm 1.3$ & $4.6 \pm 1.2$ & $5.2 \pm 1.3$ & 1.24 \\
FPG (mmol/L) & $4.43 \pm 0.78$ & $4.9 \pm 0.9$ & $5.0 \pm 0.9$ & $5.8 \pm 0.7$ & 14.46 \\
\hline
\end{tabular}

HbAlc: Haemoglobin Alc and FPG: Fasting Blood Glucose. Data are presented as mean \pm SD and compared using One-way ANOVA.

TABLE 4: Linear regression analysis between HbAlc, FPG, and selected indicators of cardiometabolic risk factors.

\begin{tabular}{|c|c|c|c|c|}
\hline \multirow{2}{*}{ Variable } & \multicolumn{2}{|c|}{ HbAlc } & \multicolumn{2}{|c|}{ FPG } \\
\hline & $\beta$ & $\mathrm{r}^{2}$ & $\beta$ & $\mathrm{r}^{2}$ \\
\hline $\mathrm{SBP}(\mathrm{mmHg})$ & 0.58 & 0.00 & $4.10 * *$ & 0.06 \\
\hline DBP (mmHg) & -0.26 & 0.00 & $2.17 *$ & 0.03 \\
\hline HbAldc-Dcct (\%) & - & - & 0.12 & 0.01 \\
\hline $\mathrm{FPG}(\mathrm{mmol} / \mathrm{L})$ & 0.07 & 0.01 & - & - \\
\hline Total cholesterol (mmol/L) & 0.07 & 0.00 & $0.33 * *$ & 0.05 \\
\hline Triglyceride $(\mathrm{mmol} / \mathrm{L})$ & $0.12 *$ & 0.03 & $0.21 * *$ & 0.05 \\
\hline $\mathrm{HDL}-\mathrm{c}(\mathrm{mmol} / \mathrm{L})$ & 0.00 & 0.00 & 0.22 & 0.04 \\
\hline LDL-c (mmol/L) & 0.02 & 0.00 & 0.01 & 0.00 \\
\hline VLDL-c (mmol/L) & $0.05 *$ & 0.03 & $0.10 * *$ & 0.05 \\
\hline MetS score & 0.06 & 0.00 & $0.56 * * *$ & 0.20 \\
\hline
\end{tabular}

$*$ Regression is significant at the 0.05 level, $* *$ regression is significant at the 0.01 level, and $* * *$ regression is significant at the 0.001 level.

TABLE 5: AUC for HbAlc and FPG in predicting MetS and its components.

\begin{tabular}{lcr}
\hline Variable & HbAlc & FPG \\
\hline MetS & $0.62(0.54-0.69)$ & $0.84(0.78-0.89)$ \\
2 or more nonglycemic criteria & $0.53(0.45-0.61)$ & $0.62(0.54-0.69)$ \\
Abdominal obesity & $0.53(0.45-0.61)$ & $0.61(0.53-0.69)$ \\
Elevated BP & $0.54(0.46-0.62)$ & $0.64(0.56-0.71)$ \\
Elevated triglyceride & $0.62(0.54-0.69)$ & $0.66(0.58-0.73)$ \\
Reduced HDL-c & $0.58(0.50-0.66)$ & $0.73(0.65-0.80)$ \\
\hline
\end{tabular}

Results are expressed as Area under Curve (confidence interval). 

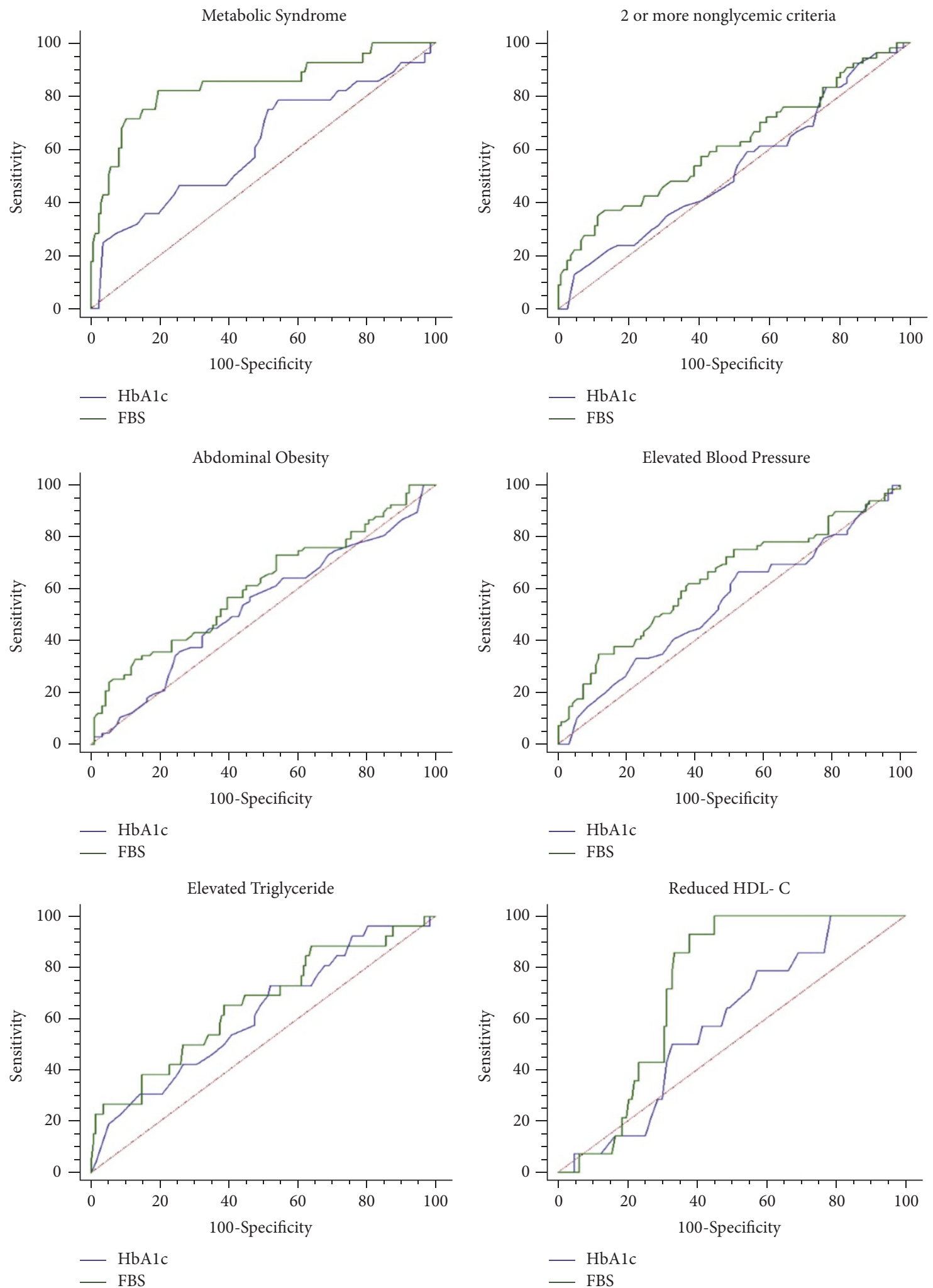

FIGURE 1: ROC curves for MetS. Compared are the relative abilities of HbAlc and FPG to identify respondents with MetS and its components. 
intraerythrocyte and extraerythrocyte environment [39], and genetic variation in hemoglobin glycation [40]. This means that, in a normoglycemic population, estimation of glucose levels will correlate better with adverse cardiometabolic outcomes than haemoglobin Alc as shown in the present study.

In this study, though there was no estimation of haemoglobin glycation index (HGI) and data on HGI among African populations that remain sparse, some studies in developed countries have revealed a lower glycation index among African Americans and Caucasians compared with Hispanics [41]. This means that, even at elevated glucose levels, formation of haemoglobin Alc among the population in the present study may have been slow and hence haemoglobin Alc did not reflect the glycemia. Hence, the subsequent absence of association between glycation and the cardiometabolic risk factors and its inability to properly predict MetS and its components compared to Fasting Blood Glucose.

Various combinations of haemoglobin variants $C$ and $S$ have been reported to falsely lower the values of HbAlc. The reported higher frequencies of these variants especially haemoglobin C among sub-Saharan Africans [42, 43] could be linked to the nonperformance of HbAlc in this study, and therefore the impact of haemoglobinopathies in this current study cannot be underestimated especially among a study population of predominantly Northern descent where the prevalence of the haemoglobin $\mathrm{C}$ has been shown to be appreciable [44].

\section{Conclusion}

This study demonstrates that, in a normoglycemic population, FPG associates better with Metabolic syndrome and other cardiometabolic risks than $\mathrm{HbAlc}$ and that fasting blood glucose estimation is shown to be the best predictor of MetS and its components among an apparently normoglycemic population.

5.1. Limitations. The estimation of haemoglobin Alc in this study was limited to only one method (Medsource Ozone Biomedicals Pvt., Ltd.) which is not listed on the 2019 NSGP certified methods list.
Abbreviations
MetS: Metabolic syndrome
HbAlc: Haemoglobin A1c
FPG: $\quad$ Fasting blood glucose
CVD: Cardiovascular disease
DM: Diabetes mellitus
SST: $\quad$ Serum separator tube
EDTA: Ethylene diamine tetraacetic acid
HDL-c: High density lipoprotein cholesterol
LDL-c: Low density lipoprotein cholesterol
VLDL-c: Very low-density lipoprotein cholesterol
HGI: Haemoglobin glycation index.

\section{Data Availability}

Data is part of a composite project data and is therefore unavailable at the moment. Data will however be provided upon request.

\section{Ethical Approval}

Ethical clearance was sought from the Ethical Review Board of the School of Allied Health Sciences and the Tamale Teaching Hospital, Tamale.

\section{Consent}

A consent was sought from each participant before being included in the study. Subjects who did not give their consent were excluded from the study. Subject confidentiality was ensured and hence consent to publish findings from data was obtained.

\section{Conflicts of Interest}

The authors declare that they have no conflicts of interest.

\section{Authors' Contributions}

This work was carried out in collaboration with all authors. Nafiu Amidu, William Kwame Boakye Ansah Owiredu, Lawrence Quaye, Peter Paul Mwinsanga Dapare, and Yussif Adams designed the study, performed the statistical analysis, wrote the protocol, and wrote the first draft of the manuscript. Nafiu Amidu, Peter Paul Mwinsanga Dapare, and Yussif Adams managed the analyses of the study. William Kwame Boakye Ansah Owiredu and Lawrence Quaye managed the literature searches. All authors read and approved the final manuscript.

\section{Acknowledgments}

Authors acknowledge the contribution of all research assistants who helped in the collection of data. The authors express their profound gratitude to all participants in the study.

\section{References}

[1] R. H. Eckel, S. M. Grundy, and P. Z. Zimmet, "The metabolic syndrome," The Lancet, vol. 365, no. 9468, pp. 1415-1428, 2005.

[2] R. A. DeFronzo and E. Ferrannini, "Insulin resistance: a multifaceted syndrome responsible for NIDDM, obesity, hypertension, dyslipidemia, and atherosclerotic cardiovascular disease," Diabetes Care, vol. 14, no. 3, pp. 173-194, 1991.

[3] M. P. Stern, "Diabetes and cardiovascular disease: the "common soil” hypothesis," Diabetes, vol. 44, no. 4, pp. 369-374, 1995.

[4] C. E. Mbada, R. A. Adedoyin, and O. Ayanniyi, "Socioeconomic status and obesity among semi-urban nigerians," Obesity Facts, vol. 2, no. 6, pp. 356-361, 2009.

[5] J. Kaur, "A comprehensive review on metabolic syndrome," Cardiology Research and Practice, vol. 2014, Article ID 943162, 21 pages, 2014 . 
[6] I. I. Ulasi, C. K. Ijoma, and O. D. Onodugo, "A communitybased study of hypertension and cardio-metabolic syndrome in semi-urban and rural communities in Nigeria," BMC Health Services Research, vol. 10, article no. 71, 2010.

[7] O. O. Oladapo, L. Salako, O. Sodiq, K. Shoyinka, K. Adedapo, and A. O. Falase, "A prevalence of cardiometabolic risk factors among a rural Yoruba south-western Nigerian population: a population-based survey," Cardiovascular Journal of Africa, vol. 21, 2010.

[8] R. Ofori-Asenso, A. A. Agyeman, and A. Laar, "Metabolic syndrome in apparently "healthy" ghanaian adults: a systematic review and meta-analysis," International Journal of Chronic Diseases, vol. 2017, Article ID 2562374, 9 pages, 2017.

[9] American Diabetes Association, "Standards of medical care in diabetes-2009," Diabetes Care, vol. 32, Suppl 1, p. S13, 2009.

[10] M. Mitka, "Hemoglobin Alc poised to become preferred test for diagnosing diabetes," Journal of the American Medical Association, vol. 301, no. 15, pp. 1528-1528, 2009.

[11] K. Malmberg, L. Rydén, and H. Wedel, "Intense metabolic control by means of insulin in patients with diabetes mellitus and acute myocardial infarction (DIGAMI 2): effects on mortality and morbidity," European Heart Journal, vol. 26, no. 7, pp. 650661, 2005.

[12] S. Park, E. Barrett-Connor, D. L. Wingard, J. Shan, and S. Edelstein, "GHb is a better predictor of cardiovascular disease than fasting or postchallenge plasma glucose in women without diabetes: the rancho bernardo study," Diabetes Care, vol. 19, no. 5, pp. 450-456, 1996.

[13] F. De Vegt, J. M. Dekker, H. G. Ruhé et al., "Hyperglycaemia is associated with all-cause and cardiovascular mortality in the Hoorn population: The Hoorn Study, Diabetologia, vol. 42, no. 8, pp. 926-931, 1999.

[14] E. Selvin, M. W. Steffes, H. Zhu et al., "Glycated hemoglobin, diabetes, and cardiovascular risk in nondiabetic adults," The New England Journal of Medicine, vol. 362, no. 9, pp. 800-811, 2010.

[15] K. Osei, S. Rhinesmith, T. Gaillard, and D. Schuster, "Is glycosylated hemoglobin alc a surrogate for metabolic syndrome in nondiabetic, first-degree relatives of african-american patients with type 2 diabetes?" The Journal of Clinical Endocrinology \& Metabolism, vol. 88, no. 10, pp. 4596-4601, 2003.

[16] C. Lorenzo, L. E. Wagenknecht, A. J. Hanley, M. J. Rewers, A. J. Karter, and S. M. Haffner, "A1C between 5.7 and $6.4 \%$ as a marker for identifying pre-diabetes, insulin sensitivity and secretion, and cardiovascular risk factors: the insulin resistance atherosclerosis study (IRAS)," Diabetes Care, vol. 33, no. 9, pp. 2104-2109, 2010.

[17] K. L. Ong, A. W. Tso, K. S. Lam, S. S. Cherny, P. C. Sham, and B. M. Cheung, "Using glycosylated hemoglobin to define the metabolic syndrome in united states adults," Diabetes Care, vol. 33, no. 8, pp. 1856-1858, 2010.

[18] E. J. Gallagher, D. Le Roith, and Z. Bloomgarden, "Review of hemoglobin A(1c) in the management of diabetes." Journal of Diabetes, vol. 1, no. 1, pp. 9-17, 2009.

[19] W. L. Roberts, B. K. De, D. Brown et al., "Effects of hemoglobin $\mathrm{C}$ and S traits on eight glycohemoglobin methods," Clinical Chemistry, vol. 48, no. 2, pp. 383-385, 2002.

[20] E. P. Joslin and C. R. Kahn, Joslin's Diabetes Mellitus, C. Ronald Kahn, G. Weir, G. King, A. Jacobson, R. Smith, and A. Moses, Eds., Lippincott Williams \& Wilkins, 2005.

[21] K. Khaw, N. Wareham, S. Bingham, R. Luben, A. Welch, and N. Day, "Association of hemoglobin Alc with cardiovascular disease and mortality in adults: the European prospective investigation into cancer in Norfolk," Annals of Internal Medicine, vol. 141, no. 6, pp. 413-420, 2004.

[22] H. C. Gerstein, J. Pogue, J. F. Mann et al., "The relationship between dysglycaemia and cardiovascular and renal risk in diabetic and non-diabetic participants in the HOPE study: a prospective epidemiological analysis," Diabetologia, vol. 48, no. 9, pp. 1749-1755, 2005.

[23] E. Succurro, M. A. Marini, F. Arturi et al., "Usefulness of hemoglobin Alc as a criterion to define the metabolic syndrome in a cohort of italian nondiabetic white subjects," American Journal of Cardiology, vol. 107, no. 11, pp. 1650-1655, 2011.

[24] K. C. Sung and E. J. Rhee, "Glycated haemoglobin as a predictor for metabolic syndrome in non-diabetic Korean adults," Diabetic Medicine, vol. 24, no. 8, pp. 848-854, 2007.

[25] H. Kim, C. Kim, E. Kim, S. Bae, and J. Park, "Usefulness of hemoglobin Alc as a criterion of dysglycemia in the definition of metabolic syndrome in Koreans," Diabetes Research and Clinical Practice, vol. 95, no. 3, pp. 333-339, 2012.

[26] M. Janghorbani and M. Amini, "Comparison of glycated hemoglobin with fasting plasma glucose in definition of glycemic component of the metabolic syndrome in an Iranian population," Diabetes \& Metabolic Syndrome: Clinical Research \& Reviews, vol. 6, no. 3, pp. 136-139, 2012.

[27] J. Dilley, A. Ganesan, R. Deepa et al., "Association of A1C with cardiovascular disease and metabolic syndrome in asian indians with normal glucose tolerance," Diabetes Care, vol. 30, no. 6, pp. 1527-1532, 2007.

[28] Q. M. Nguyen, S. R. Srinivasan, J. Xu, W. Chen, and G. S. Berenson, "Distribution and cardiovascular risk correlates of hemoglobin Alc in nondiabetic younger adults: the Bogalusa Heart Study," Metabolism, vol. 57, no. 11, pp. 1487-1492, 2008.

[29] W. Owiredu, N. Amidu, E. Gockah-Adapoe, and R. Ephraim, "The prevalence of metabolic syndrome among active sportsmen/sportswomen and sedentary workers in the Kumasi metropolis," Journal of Science and Technology (Ghana), vol. 31, no. 1, 2011.

[30] A. M. Kirkendall, W. E. Connor, F. Abboud, S. P. Rastogi, T. A. Anderson, and M. Fry, "The effect of dietary sodium chloride on blood pressure, body fluids, electrolytes, renal function, and serum lipids of normotensive man," Translational Research, vol. 87, no. 3, pp. 418-434, 1976.

[31] K. G. Alberti, R. H. Eckel, S. M. Grundy et al., "Harmonizing the metabolic syndrome: a joint interim statement of the international diabetes federation task force on epidemiology and prevention; National heart, lung, and blood institute; American heart association; World heart federation; International atherosclerosis society; and international association for the study of obesity," Circulation, vol. 120, no. 16, pp. 1640-1645, 2009.

[32] E. Ferrannini, "Is insulin resistance the cause of the metabolic syndrome?” Annals of Medicine, vol. 38, no. 1, pp. 42-51, 2009.

[33] S. R. Kashyap and R. A. Defronzo, "The insulin resistance syndrome: physiological considerations," Diabetes and Vascular Disease Research, vol. 4, no. 1, pp. 13-19, 2016.

[34] M. Brownlee, "Biochemistry and molecular cell biology of diabetic complications," Nature, vol. 414, no. 6865, pp. 813-820, 2001.

[35] S. H. Park, J. S. Yoon, K. C. Won, and H. W. Lee, "Usefulness of glycated hemoglobin as diagnostic criteria for metabolic syndrome," Journal of Korean Medical Science, vol. 27, no. 9, pp. 1057-1061, 2012. 
[36] X. Zhou, Z. Pang, W. Gao et al., "Performance of an A1C and fasting capillary blood glucose test for screening newly diagnosed diabetes and pre-diabetes defined by an oral glucose tolerance test in Qingdao, China," Diabetes Care, vol. 33, no. 3, pp. 545-550, 2010.

[37] L. Monnier, H. Lapinski, and C. Colette, "Contributions of fasting and postprandial plasma glucose increments to the overall diurnal hyperglycemia of type 2 diabetic patients: variations with increasing levels of HbAlc," Diabetes Care, vol. 26, no. 3, pp. 881-885, 2003.

[38] R. M. Cohen, R. S. Franco, P. K. Khera et al., "Red cell life span heterogeneity in hematologically normal people is sufficient to alter HbAlc," Blood, vol. 112, no. 10, pp. 4284-4291, 2008.

[39] P. K. Khera, C. H. Joiner, A. Carruthers et al., "Evidence for Interindividual Heterogeneity in the Glucose Gradient Across the Human Red Blood Cell Membrane and Its Relationship to Hemoglobin Glycation," Diabetes, vol. 57, no. 9, pp. 2445-2452, 2008.

[40] R. M. Cohen, H. Snieder, C. J. Lindsell et al., "Evidence for independent heritability of the glycation gap (glycosylation gap) fraction of HbAlc in nondiabetic twins," Diabetes Care, vol. 29, no. 8, pp. 1739-1743, 2006.

[41] J. M. Boltri, I. S. Okosun, M. Davis-Smith, and R. L. Vogel, "Hemoglobin A1C levels in diagnosed and undiagnosed Black, Hispanic, and White persons with diabetes: Results from NHANES 1999-2000," Ethnicity \& Disease, vol. 15, no. 4, pp. 562-567, 2005.

[42] F. B. Piel, A. P. Patil, R. E. Howes et al., "Global epidemiology of Sickle haemoglobin in neonates: a contemporary geostatistical model-based map and population estimates," The Lancet, vol. 381, no. 9861, pp. 142-151, 2013.

[43] B. Modell and M. Darlison, "Global epidemiology of haemoglobin disorders and derived service indicators," Bulletin of the World Health Organization, vol. 86, no. 6, pp. 480-487, 2008.

[44] F. Mockenhaupt, S. Ehrhardt, J. Cramer et al., "Hemoglobin C and resistance to severe malaria in ghanaian children," The Journal of Infectious Diseases, vol. 190, no. 5, pp. 1006-1009, 2004. 


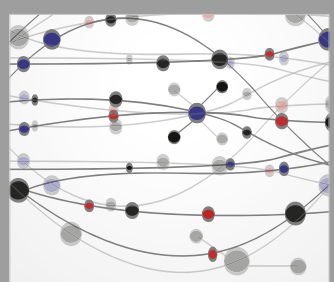

The Scientific World Journal
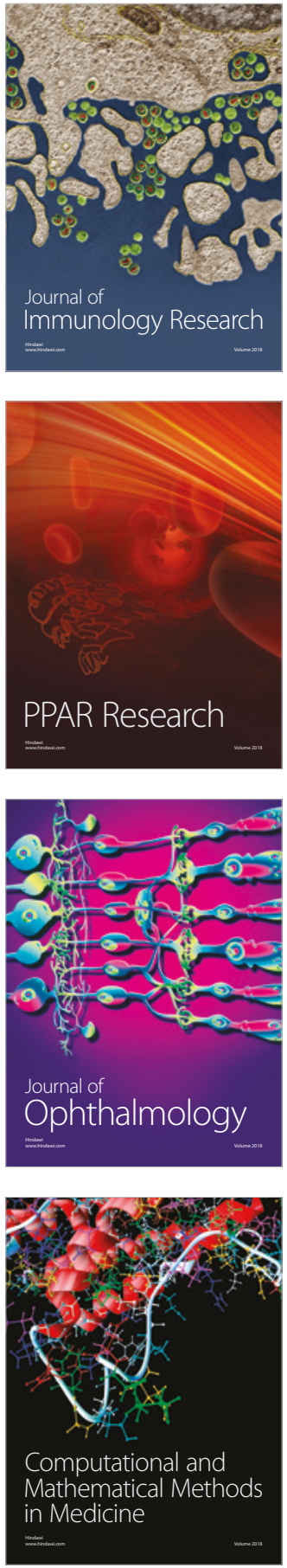

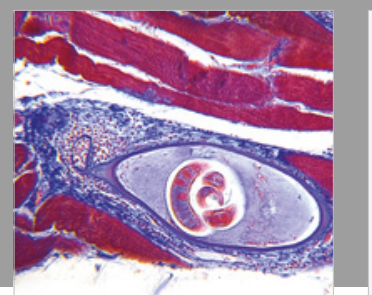

Gastroenterology Research and Practice

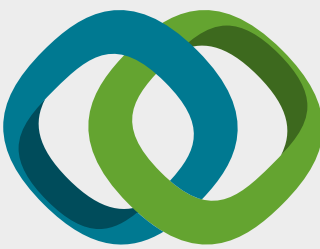

\section{Hindawi}

Submit your manuscripts at

www.hindawi.com
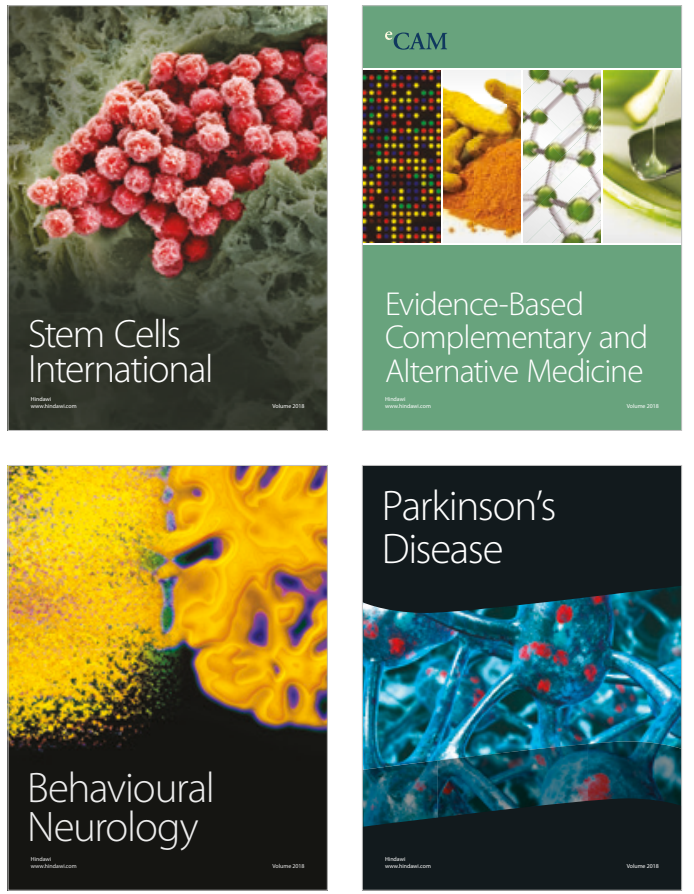

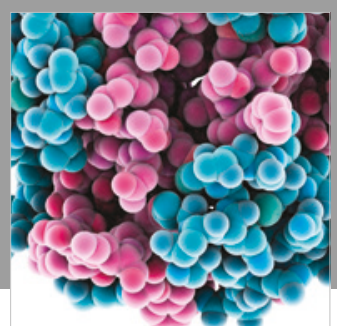

ournal of

Diabetes Research

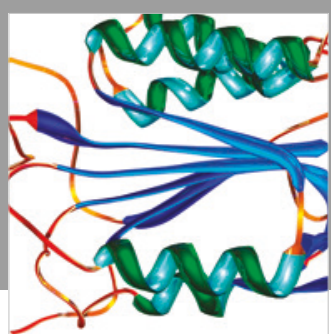

Disease Markers
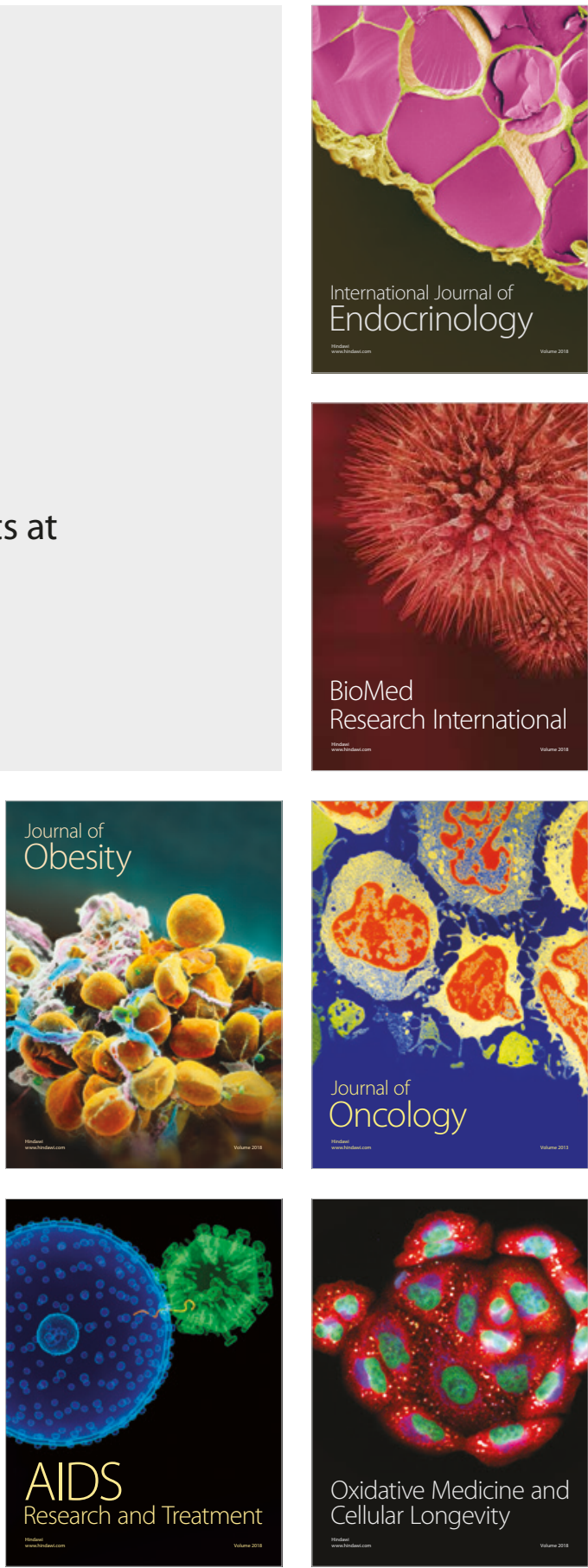